\title{
Nerve growth factor regulates liver cancer cell polarity and motility
}

\author{
HAIHUA LIN ${ }^{1}$, HUANJUN HUANG $^{2}$, YUHONG YU ${ }^{1}$, WEIBIN CHEN ${ }^{1}$, \\ SHAOMIN ZHANG ${ }^{1}$ and YUANZHI ZHANG ${ }^{1}$ \\ ${ }^{1}$ Department of Gastroenterology, Yantian District People's Hospital, Shenzhen, \\ Guangdong 518000; ${ }^{2}$ Department of Gastroenterology, Tongji Hospital, Tongji Medical College, \\ Huazhong University of Science and Technology, Wuhan, Hubei 430030, P.R. China
}

Received June 23, 2020; Accepted January 7, 2021

DOI: $10.3892 / \mathrm{mmr} .2021 .11927$

\begin{abstract}
Nerve growth factor (NGF), a prototypical neurotrophic factor essential for neuronal cell proliferation and survival, has been implicated as a marker of tumor progression, as well as a potential target for novel therapeutic approaches in cancer. To investigate the functional potential of NGF in liver cancer in the present study, a stable NGF-overexpressing HepG2 cell line was generated. The scratch-wound assay was used to investigate cell motility and polarity. Western blotting was performed to evaluate the expression levels of epithelial-mesenchymal transition (EMT)-related proteins, including E-cadherin, N-cadherin and vimentin. Moreover, immunofluorescence was performed to investigate the arrangement of the actin cytoskeleton. Cell anoikis resistance was examined using a suspension culture model and cell apoptosis was examined via flow cytometry. The present results indicated that NGF overexpression in HepG2 cells disrupted HepG2 cell polarity and promoted cell motility. Furthermore, NGF overexpression induced EMT and actin cytoskeleton rearrangement in HepG2 cells, as well as enhanced anoikis resistance and prevented cellular apoptosis. Notably, a tropomyosin receptor kinase A receptor inhibitor blocked NGF-induced cell motility and apoptosis. Therefore, it was suggested that NGF serves a critical role in the invasion and metastasis of liver cancer. The use of NGF as a biomarker or potential new target could
\end{abstract}

Correspondence to: Dr Haihua Lin, Department of Gastroenterology, Yantian District People's Hospital, Inpatient Department Building, 2010 Wutong Road, Shenzhen, Guangdong 518000, P.R. China E-mail: haihua19860913@163.com

Abbreviations: NGF, nerve growth factor; EMT, epithelialmesenchymal transition; Trk, tropomyosin receptor kinase; p75NTR, p75 neurotrophin receptor

Key words: NGF, cell polarity, EMT, actin cytoskeleton, anoikis, liver cancer lead to the development of novel factors for diagnosis or for improving therapeutic strategies in liver cancer.

\section{Introduction}

Liver cancer is the sixth most common types of cancer and the fourth leading cause of cancer-associated morality worldwide $(1,2)$. China had the highest number of primary liver cancer cases globally, with an incidence rate of 17.8 cases/100,000 inhabitants in 2014 (3). Despite significant progress in liver cancer therapeutics, the recognition of cancer cell invasion into the surrounding environment and metastatic spread remains a major research challenge and clinical problem. Moreover, the underlying molecular mechanisms that initiate cancer cell invasion and metastases remain poorly understood. It has been reported that cell polarity defects, which are associated with cell viability, motility and adhesion ability, can serve as initiators of cancer cell invasion and metastatic spread (4-8). Furthermore, epithelial-mesenchymal transition (EMT), which can mutually interact with the actin cytoskeleton and cell polarity, is critical during the early steps of metastasis and invasion (9-12). These processes appear to be associated with altered expression of adhesion molecules and dysregulation of growth factor signaling.

Nerve growth factor (NGF) is a prototypical neurotrophic factor that is essential for neuronal cell growth and survival $(13,14)$. NGF can interact with its receptor tropomyosin receptor kinase A (TrkA) with a high affinity, whereas it interacts with p75 neurotrophin receptor (p75NTR) with a low affinity (15). Binding of NGF to TrkA results in intracellular signaling and leads to cell differentiation and survival. Conversely, the interaction of NGF with p75NTR activates Jun-N-terminal kinase and ceramide to promote apoptosis $(16,17)$. Although NGF is undetectable in adult and developing livers, its expression is markedly elevated in liver cancer $(18,19)$. In recent years, several studies have reported that NGF, together with TrkA and p75NTR, are involved in aspects of tumor biology, including growth, invasion and metastasis (20-23). NGF has also been implicated as a marker of tumor progression and is a potential target for novel therapeutic approaches in cancer $(24,25)$. 
HepG2 cells are non-tumorigenic cells with high proliferation rates and have been used to evaluate cell polarity and motility as an in vitro model in several studies $(26,27)$. The present study generated a NGF-overexpressing HepG2 cell line to investigate the functional potential of NGF in liver cancer, and subsequently examined the regulatory mechanism of NGF on cell motility, polarity and EMT, as well as the underlying effects on cytoskeleton rearrangements and apoptosis. The present results could elucidate the possible role of NGF in hepatic carcinogenesis and provide novel insights into the treatment of liver cancer.

\section{Materials and methods}

Cell culture. The HepG2 cell line used in this study was purchased from the China Center for Type Culture Collection and was authenticated by short tandem repeat profiling. The cells were cultured in DMEM containing 10\% FBS (Thermo Fisher Scientific, Inc.), $100 \mathrm{U} / \mathrm{ml}$ penicillin $\mathrm{G}$ and $100 \mu \mathrm{g} / \mathrm{ml}$ streptomycin at $37^{\circ} \mathrm{C}$ with $5 \% \mathrm{CO}_{2}$ and $95 \% \mathrm{O}_{2}$.

Plasmid transfections. Lipofectamine ${ }^{\circledR} 2000$ (Invitrogen; Thermo Fisher Scientific, Inc.) was used to transfect cells according to the manufacturer's protocol. In brief, $4 \mu \mathrm{g}$ pcDNA3 vector (pcDNA3-control) or pcDNA3-NGF plasmid (gift from Professor Philip Barker, McGill University, Montreal, Canada) was mixed with $10 \mu$ l Lipofectamine for $20 \mathrm{~min}$ at room temperatures and the mixture was transfected into $90 \%$ confluent HepG2 cells for $1 \mathrm{~h}$. The transfected cells were cultured at $37^{\circ} \mathrm{C}$ in DMEM for $6 \mathrm{~h}$, and then in DMEM with $10 \%$ FBS for $48 \mathrm{~h}$ at $37^{\circ} \mathrm{C}$ with $5 \% \mathrm{CO}_{2}$ and $95 \% \mathrm{O}_{2}$. To select stable transfectants, cells were cultured at $37^{\circ} \mathrm{C}$ in DMEM with $600 \mu \mathrm{g} / \mathrm{ml} \mathrm{G} 418$ for 4 weeks to generate a stable NGF-overexpressing HepG2 cell line. After a single colony of stable cells was selected for further culture, the concentration of G418 was subsequently reduced by half and maintained in cultivation. One pcNA3-control and two different pcDNA3-NGF stable cell lines were selected for subsequent studies.

Wound healing assays. In brief, cultured cells with DMEM containing $10 \%$ FBS were grown to $100 \%$ confluence on plastic dishes or coverslips (for microscopic studies) and scratched using a $10 \mu \mathrm{l}$ pipette tip. Debris was removed from the wound and washed out with PBS. The cells were then cultured with DMEM containing 10\% FBS and the images were acquired at 0,24 and $48 \mathrm{~h}$ using an inverted light microscope (IX83; Olympus Corporation; magnification, x10) after cells were wounded. Wound closure was quantitatively analyzed using ImageJ Fiji software (version 1.53g 4; National Institutes of Health). Each test was performed in triplicate. A total of $10 \mathrm{mg} / 1$ CEP701 (Sigma-Aldrich Merck KGaA) was added after cells were scratched and maintained in the culture medium at $37^{\circ} \mathrm{C}$ until images at different time points were acquired.

Golgi reorientation polarity assays. As previously described $(28,29)$, the wounded cells were fixed with cold $4 \%$ paraformaldehyde at $4^{\circ} \mathrm{C}$ for $10 \mathrm{~min}$ and stained with the cis-Golgi matrix protein of $130 \mathrm{kDa}$ (GM130) to visualize Golgi positioning after $16 \mathrm{~h}$. A total of $7 \mu \mathrm{g} / \mathrm{ml}$ anti-GM130 antibody (cat. no. ab169276; Abcam) were incubated with cells at $4^{\circ} \mathrm{C}$ overnight. The appropriate secondary antibody conjugated with rhodamine were incubated for $1 \mathrm{~h}$ at room temperature. Then, 4'6-diamidino-2-phenyl-indole (DAPI) staining was performed as previously described (29). Cell images were acquired using a Nikon TE2000S fluorescence microscope (magnification, x20) and were analyzed using ImageJ Fiji software (version 1.53g 4; National Institutes of Health). Cell orientation was determined only for cells at the wound edge. The cell was divided into three $120^{\circ}$ regions, with one region facing the wound edge. The cell was recognized to possess an aligned Golgi only when its Golgi realigned to the $120^{\circ}$ region facing the wound edge. The cell positioning angle was calculated between a line along the long axis of the nucleus and a line tracing the wound front. For example, cells aligned perpendicular to the leading edge demonstrated a nearly $90^{\circ}$ orientation, whereas cells aligned parallel to the wound front had a $0^{\circ}$ orientation. For each experiment, $\geq 20$ cells were examined.

Western blot analysis. Whole-cell protein was extracted with cell lysis buffer (Cell Signaling Technology, Inc.). Protein concentrations were determined via bicinchoninic acid protein assay kit (Pierce; Thermo Fisher Scientific, Inc.). A total of $50 \mu \mathrm{g}$ protein from whole-cell lysates were solubilized in SDS sample buffer and separated on SDS $12.5 \%$ polyacrylamide gels. The proteins were transferred to polyvinylidene difluoride membranes and incubated with blocking solution (Tris buffer containing $0.1 \%$ Tween-20 and 5\% non-fat dry milk) at room temperature for $1 \mathrm{~h}$. The membrane was then incubated with the primary antibody at $4^{\circ} \mathrm{C}$ overnight and the secondary antibody at room temperature for $1 \mathrm{~h}$. The primary antibodies against NGF (1:1,000; cat. no. sc32300; Santa Cruz Biotechnology Inc.), E-cadherin (1:1,000; cat. no. 14472; Cell Signaling Technology, Inc.), N-cadherin (1:1,000; cat. no. 4061; Cell Signaling Technology, Inc.), vimentin $(1: 1,000$; cat. no. 3932; Cell Signaling Technology, Inc.), F-actin (1:1,000; cat. no. ab130935; Abcam) and $\beta$-actin (1:1,000; cat. no. sc69879; Santa Cruz Biotechnology Inc.) were used for different proteins with horseradish peroxidase (HRP)-conjugated secondary antibodies (all 1:2,000; cat. nos. ab205718, ab205719 and ab205720; all Abcam). $\beta$-actin protein was detected as a loading control for whole-cell protein. An enhanced chemiluminescent substrate for detection of HRP (cat. no. 32209; Thermo Fisher Scientific, Inc.) was used to visualize the bands with ChemiDoc imaging system (Bio-Rad Laboratories, Inc.). The bands were analyzed with ImageJ Fiji software (version 1.53g 4; National Institutes of Health).

Immunofluorescence and confocal imaging. Briefly, HepG2 and HepG2-NGF cells were plated onto sterile coverslips and incubated in a humidified chamber at $37^{\circ} \mathrm{C}$. A total of $10 \mathrm{mg} / \mathrm{l}$ CEP701 (Sigma-Aldrich; Merck KGaA) was added at $37^{\circ} \mathrm{C}$ $24 \mathrm{~h}$ before fixation. After $24 \mathrm{~h}$, the cells were washed, fixed with cold $4 \%$ paraformaldehyde at $4^{\circ} \mathrm{C}$ for $10 \mathrm{~min}$ and permeabilized with $0.2 \%$ Triton X-100. After each experiment, cells were washed three times for $5 \mathrm{~min}$ in PBS, then blocked with 5\% BSA (Abcam) in PBS for $30 \mathrm{~min}$ at room temperature and incubated with anti-NGF (1:250; cat. no. ab52918; Abcam) or 
A

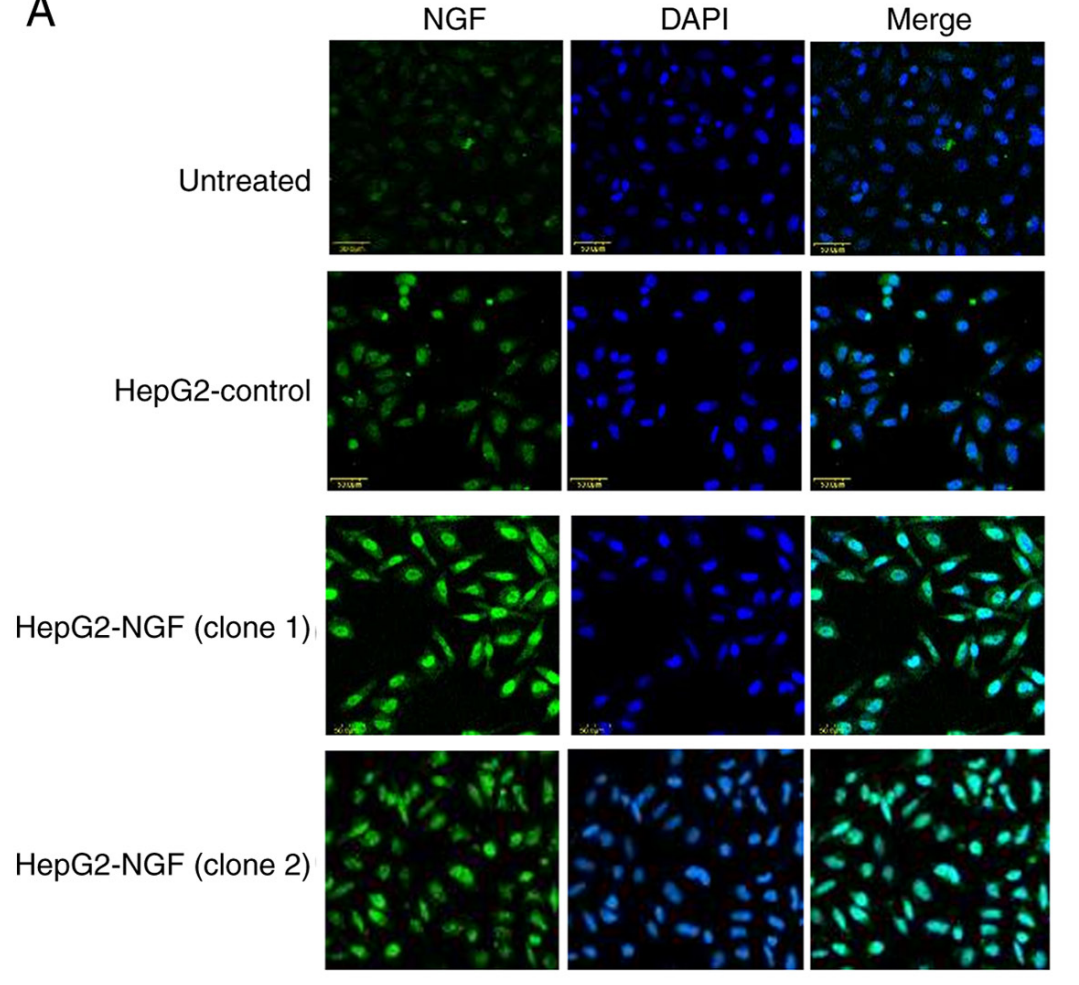

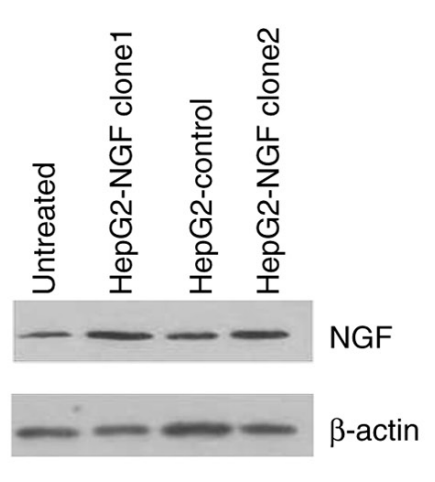

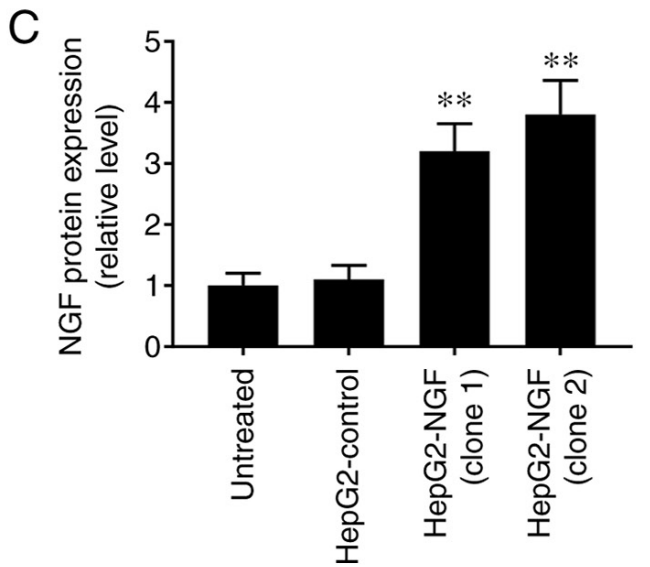

Figure 1. Overexpression of NGF in HepG2 cells. (A) HepG2 cells were transfected with pcDNA3-control (HepG2-control) and pcDNA3-NGF (HepG2-NGF), immunolabelled with NGF (green) and then imaged with confocal microscopy. Nuclei are stained with DAPI (blue). (B) Representative western blotting image for NGF protein expression with $\beta$-actin loading control. (C) Normalized NGF protein signals were analyzed using one-way ANOVA. Scale bar, 50 mm. Data are presented as the mean $\pm \mathrm{SEM}, \mathrm{n}=5$. ${ }^{* *} \mathrm{P}<0.01 \mathrm{vs}$. HepG2-control and untreated groups. NGF, nerve growth factor.

$5 \mu \mathrm{g} / \mathrm{ml}$ anti-F-actin antibody (cat. no. ab130935; Abcam) at $4^{\circ} \mathrm{C}$ overnight. Cells were then treated with $10 \mu \mathrm{g} / \mathrm{ml}$ corresponding secondary antibody conjugated with FITC (cat. no. F-2765) or rhodamine (cat. no. R-6393; both Invitrogen; Thermo Fisher Scientific, Inc.) for $1 \mathrm{~h}$ at room temperature. Nuclear staining was performed by incubating cells with $0.4 \mu \mathrm{mol} / 1$ DAPI for $2 \mathrm{~min}$ at room temperature. Subsequently, cells were examined under a confocal microscope with 10x or 60x oil objectives (Olympus Corporation).

Anoikis assay. The anoikis assay was performed as described by Frisch and Francis (30) by plating cells into ultra-low attachment plates. Cells were plated at a density of $100 \times 10^{6}$ cells, onto $60-\mathrm{mm}$ polyHEMA $(10 \mathrm{mg} / \mathrm{ml})$-coated Petri dishes. After culturing for $24 \mathrm{~h}$, images were obtained using an inverted light microscope (cat. no. IX83; Olympus Corporation; magnification, $\mathrm{x} 10$ ) and cells were collected for flow cytometry (Attune NxT; Thermo Fisher Scientific, Inc.). BD FACS Diva software 6.0 (BD Biosciences) was used to analysis the apoptosis ratio. In order to investigate the effect of CEP701, the cells were treated at $37^{\circ} \mathrm{C}$ with $10 \mathrm{mg} / 1 \mathrm{CEP} 701$ for $24 \mathrm{~h}$ and images were acquired.

Statistical analysis. Data are presented as the mean \pm SEM $(n \geq 3)$ P-values were calculated using an ordinary one-way ANOVA, which was followed by a Tukey's test. $\mathrm{P}<0.05$ was considered to indicate a statistically significant difference.

\section{Results}

NGF expression in HepG2-pcDNA3-NGF cells. The pcDNA3-control and pcDNA3-NGF were stably transfected into HepG2 cells and NGF expression was detected via western blotting and immunofluorescence. The fluorescence intensity level of NGF was notably higher in the two NGF-overexpressing HepG2 clones (HepG2-NGF clone 1 and clone 2) compared with that in the uninfected cells or pcDNA3-control cells (HepG2-control) (Fig. 1A). Furthermore, western blotting demonstrated that the NGF protein expression level in HepG2-NGF cells was increased by $>3$ fold when compared with that observed in the control group (HepG2-control) (Fig. 1B and C). These results indicated that the NGF was successfully transfected into HepG2 cells.

Effect of NGF regulation on cell motility and polarity. The effects of NGF on cell motility and polarity were subsequently examined after establishing the HepG2-NGF stable cell line. As presented in Fig. 2, $48 \mathrm{~h}$ after the cells were scratched, the relative wound width of control cells was $\sim 50 \%$ of the original scratch width, compared with 27 and $23 \%$ in the two different HepG2-NGF clones, indicating that NGF overexpression in both HepG2-NGF cell clones can significantly promote HepG2 cell motility.

The Golgi serves an important role in protein trafficking to the leading cell edge and can function as a cell polarization 
A

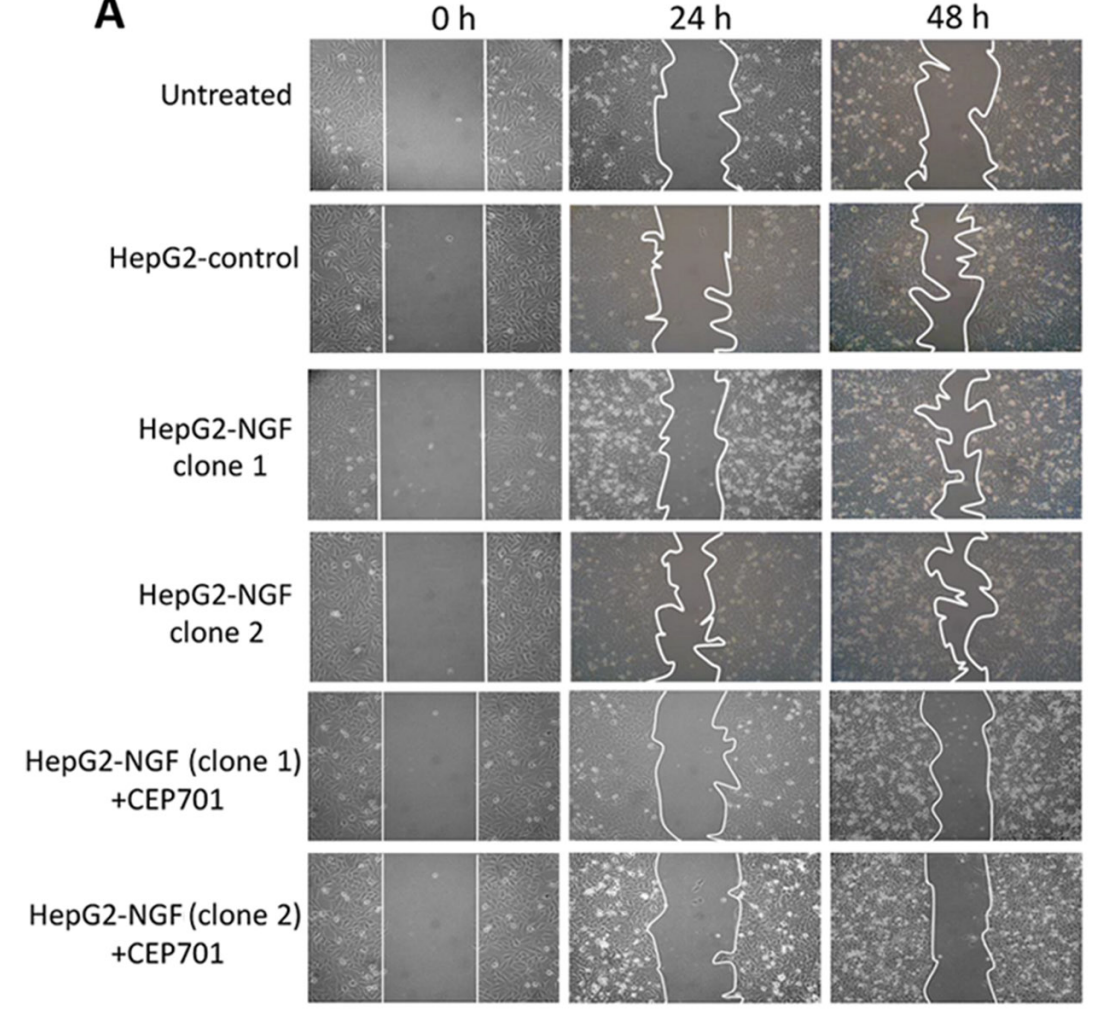

B

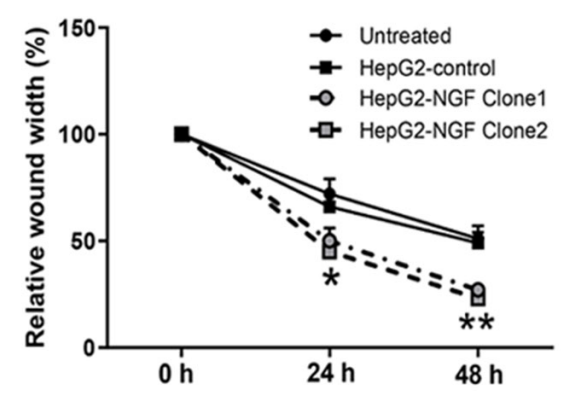

C

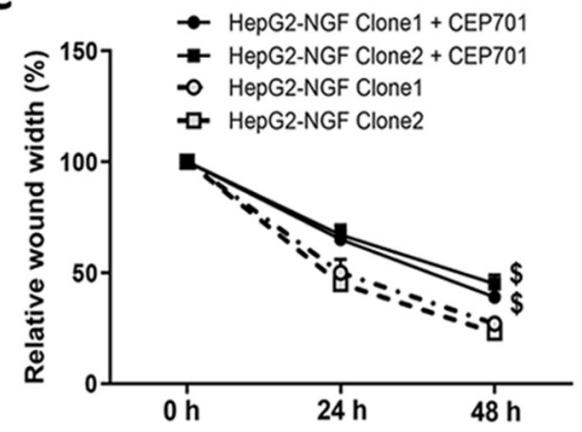

Figure 2. Effect of NGF on cell motility. Wound healing assay were used to examine the cell motility. (A) Images were acquired at 0,24 and $48 \mathrm{~h}$ using an inverted microscope (10x magnification) after the confluent cells were wounded by scratching cell sheets with a $10 \mu 1$ pipette tip. CEP701 was added at $0 \mathrm{~h}$. (B) The wound closure was quantitatively analyzed using ImageJ software by outlining and assessing the unhealed area in the wound images. Data are presented as the mean \pm SEM, $n=4$. ${ }^{*} \mathrm{P}<0.05,{ }^{* *} \mathrm{P}<0.01$ vs. HepG2-control and untreated group (one-way ANOVA). (C) Effect of CEP701 on cell motility. Data are presented as the mean \pm SEM, $n=4 .{ }^{\$} \mathrm{P}<0.05$ vs. HepG2-NGF cells without CEP701 treatment (one-way ANOVA). NGF, nerve growth factor.

marker $(29,31,32)$. Therefore, Golgi reorientation was examined in HepG2-NGF cells when cell polarity was stimulated. A total of $16 \mathrm{~h}$ after cells were scratched, they were fixed and stained for the protein GM130. The majority of untreated HepG2 cells and pcDNA3-control cells were polarized in a direction perpendicular to the wound (the average orientation was nearly $70^{\circ}$ to the wound). Moreover, $\sim 70 \%$ of untreated HepG2 cells and pcDNA3-control cells demonstrated proper orientation (reoriented in front of the nucleus) and were realigned to the $120^{\circ}$ region facing the direction of movement after scratching was performed (Fig. 3). By contrast, HepG2-NGF cells presented only $42 \%$ of cells with proper Golgi positioning and only a $30^{\circ}$ orientation relative to the wound, indicating defective cell polarity after NGF overexpression in these cells (Fig. 3).

NGF overexpression initiates EMT. In cancer cells, loss of the apical-basal polarity and acquisition of the migratory phenotype is considered a subtype of EMT, which is suggested to promote cancer cell migration and invasion (9-11). Based on the results from Figs. 2 and 3, it was considered that there may be a potential relationship between NGF and the EMT process. Hence, the effects of NGF on EMT were subsequently examined. Western blotting results indicated that NGF overexpression induced the loss of E-cadherin (Fig. 4A), as well as the production of $\mathrm{N}$-cadherin (Fig. 4B) and vimentin (Fig. 4C) in HepG2 cells. These results suggested that NGF could induce a cadherin switch and initiate EMT in HepG2 cells.

Rearrangement of the actin cytoskeleton in NGFoverexpressing HepG2 cells. In addition to disrupting cell-cell adhesions and the overall loss of epithelial homeostasis, the altered functions of the polarity determinants can result in cytoskeleton rearrangements and regulate actin dynamics $(33,34)$. Herein, it was detected whether NGF can affect the F-actin cytoskeletal arrangement and protein expression. In control cells, F-actin was organized in a circular pattern and formed circumferential bundles with visible slim central fibers, as visualized using immunofluorescence and confocal laser microscopy (Fig. 5A). However, in HepG2-NGF cells, F-actin was redistributed into strong central fibers (stress fibers) and these stress fibers were arranged parallel to the elongated shape of a cell. Furthermore, the F-actin protein expression level was increased in NGF-overexpressing HepG2 cells (Fig. 5B). These results indicated that NGF overexpression can change the actin cytoskeleton arrangement in HepG2 cells, even in the absence of stress or stretch induction.

Effect of NGF overexpression on anoikis resistance and apoptosis. In a previous study, NGF signaling was reported to alter cell death and survival in various cancer cells $(15,35)$. Therefore, the effect of NGF on cell anoikis resistance and 


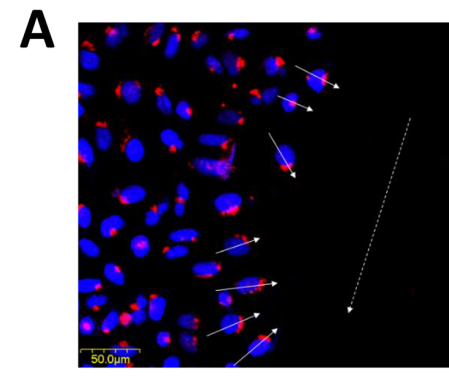

Untreated

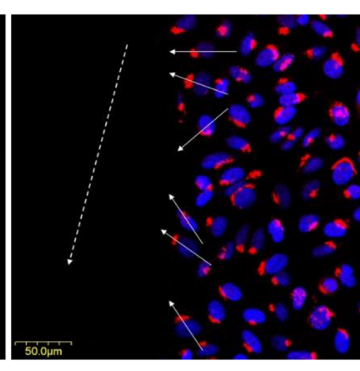

HepG2-control

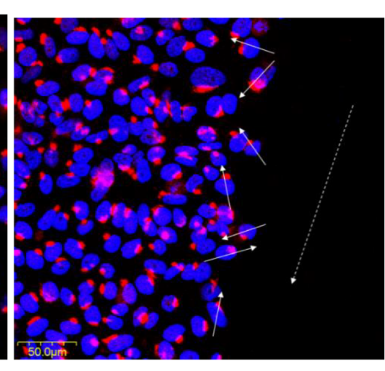

HepG2-NGF
B

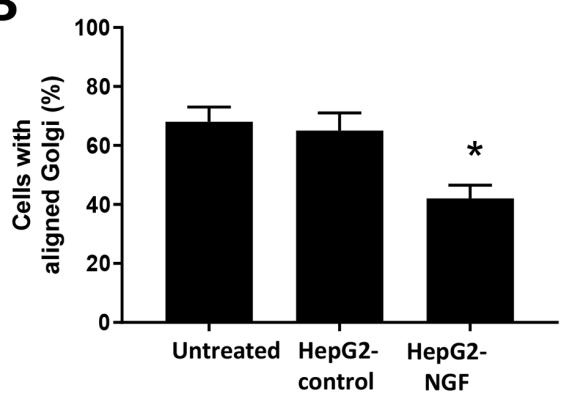

C

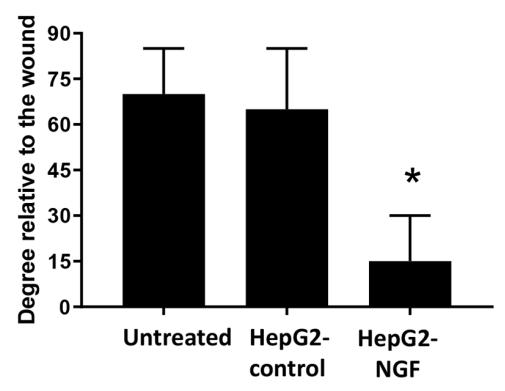

Figure 3. Effect of NGF on cell apical-basal polarity. (A) Golgi (red) and DAPI (blue) immunofluorescence staining in HepG2 cells. Arrows: Golgi positioning relative to the wound designated with a dashed line. (B) Bar graph presenting the percentage of cells with aligned Golgi ( $\mathrm{n}=20$ cells per experimental group). (C) Bar graph depicting cell positioning in degrees relative to the wound ( $\mathrm{n}=20$ cells per experimental group). Scale bar, $50 \mu \mathrm{m}$. Data are presented as the mean \pm SEM, $n=4$ experiments. " $\mathrm{P}<0.05$ vs. HepG2-control and untreated group (one-way ANOVA). NGF, nerve growth factor.

A
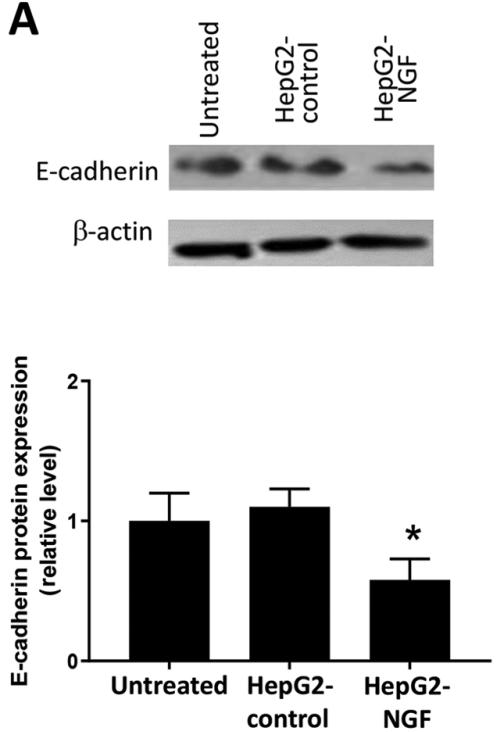

B
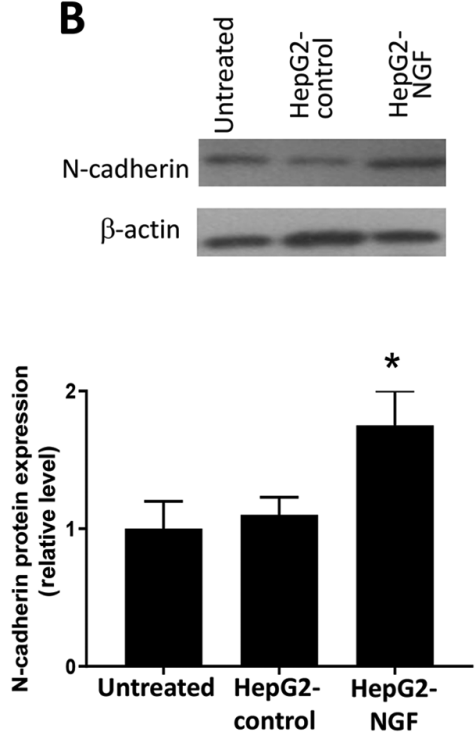

C
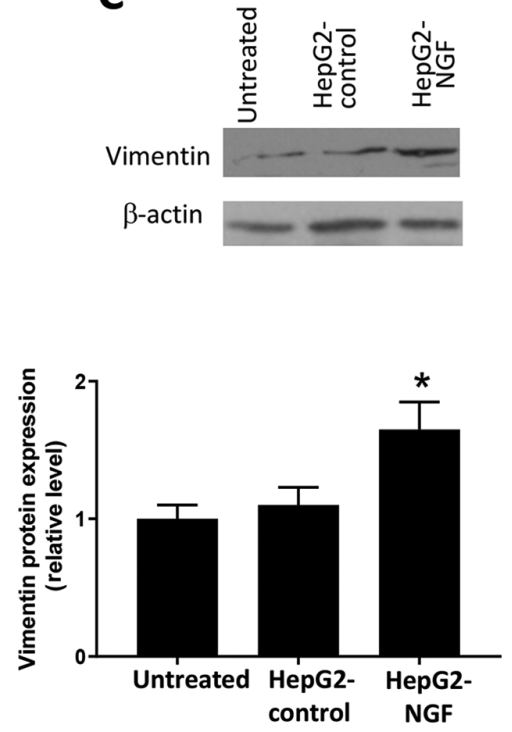

Figure 4. Western blot analyses of the protein expression levels of E-cadherin, N-cadherin and vimentin. (A) E-cadherin, (B) N-cadherin and (C) vimentin expression levels were normalized to $\beta$-actin expression levels. Data were obtained from $\geq 3$ different experiments. Data are presented as the mean \pm SEM. ${ }^{*} \mathrm{P}<0.05$ vs. HepG2-control and untreated group (one-way ANOVA). NGF, nerve growth factor.

apoptosis was examined in HepG2 cells cultured in a suspension culture model. As presented in Fig. 6, compared with HepG2-control cells, after culturing for $24 \mathrm{~h}$ in ultra-low attachment plates, the diameters of HepG2-NGF cell colonies were considerably larger and the apoptosis ratios were lower in HepG2-NGF cells. This indicated that NGF overexpression could enhance anoikis resistance and prevent apoptosis in HepG2 cells.
Effects of the TrkA receptor inhibitor CEP701 on cell motility and apoptosis. To determine whether NGF regulates cell motility by interacting with its receptors, the TrkA receptor inhibitor CEP701 (10 mg/l) was used in wound healing assays in which cells were scratched, and cell motility was evaluated. A total of $48 \mathrm{~h}$ after cells were wounded, the relative wound width of both HepG2-NGF clones was considerably higher compared with that of untreated cells, suggesting that 
A
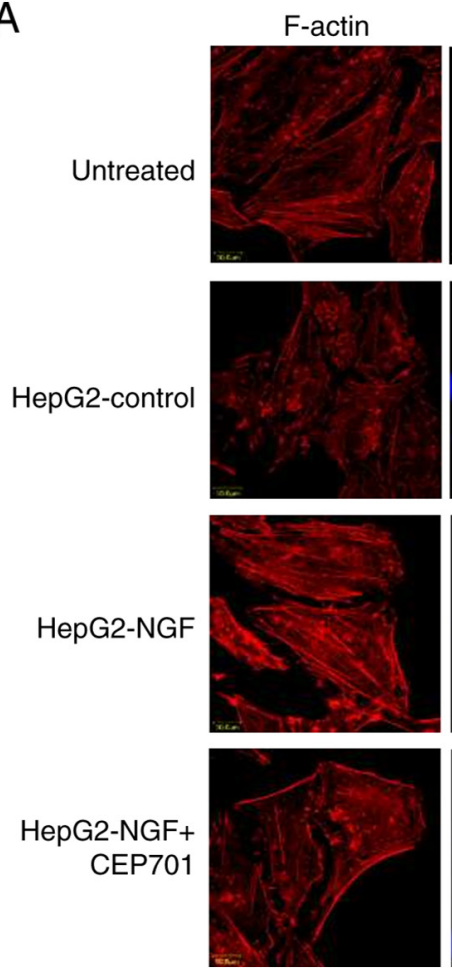

DAPI
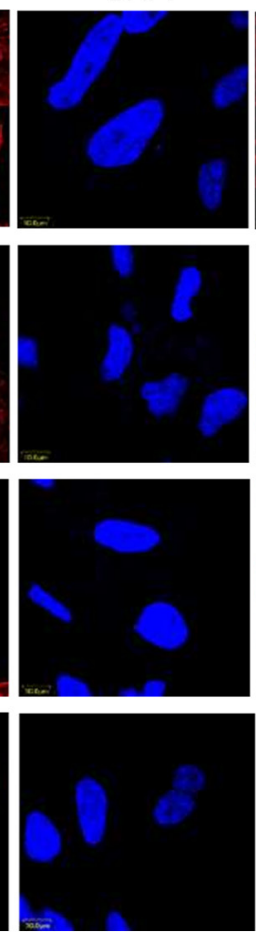
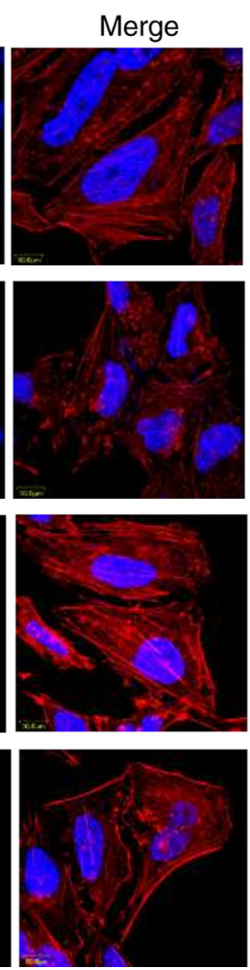

B
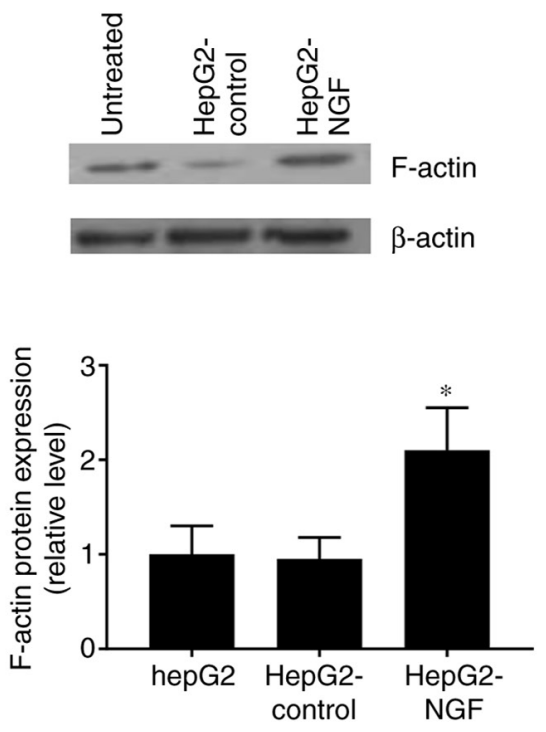

Figure 5. Effect of NGF on F-actin arrangement and expression. (A) Immunofluorescence staining of F-actin (red) in NGF transfected HepG2 cells. Nuclei were stained with DAPI (blue). (B) Western blot analyses of protein expression of F-actin. F-actin expression levels were normalized to $\beta$-actin expression levels. Data were obtained from three different experiments. Scale bar, $10 \mu \mathrm{m}$. Data are presented as the mean $\pm \mathrm{SEM}$. ${ }^{*} \mathrm{P}<0.05 \mathrm{vs}$. HepG2-control and untreated group (one-way ANOVA). NGF, nerve growth factor.

A

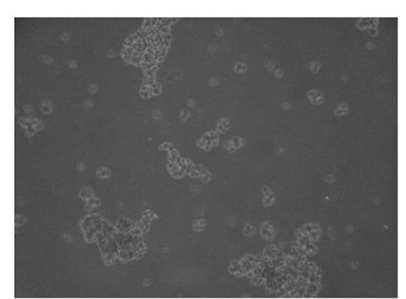

Untreated

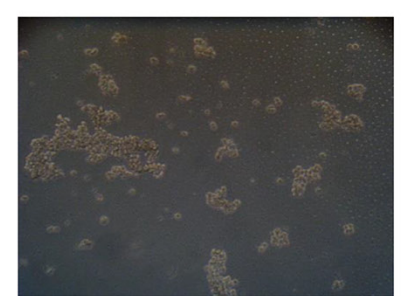

HepG2-control

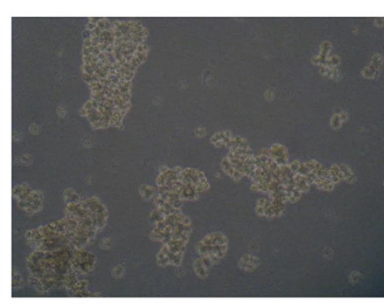

HepG2-NGF (clone1)

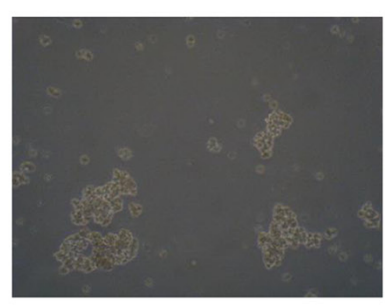

HepG2-NGF + CEP701
B

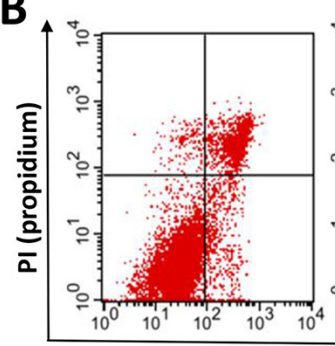

Untreated

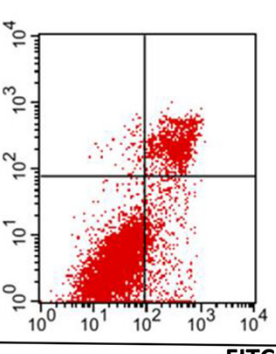

HepG2-control

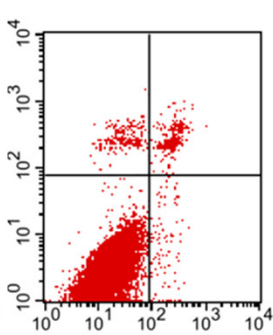

HepG2-NGF

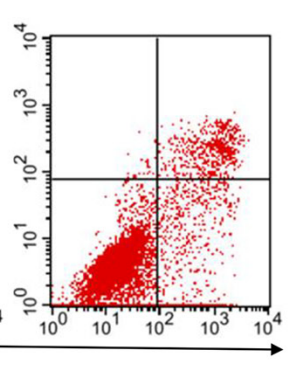

HepG2-NGF+CEP701
C

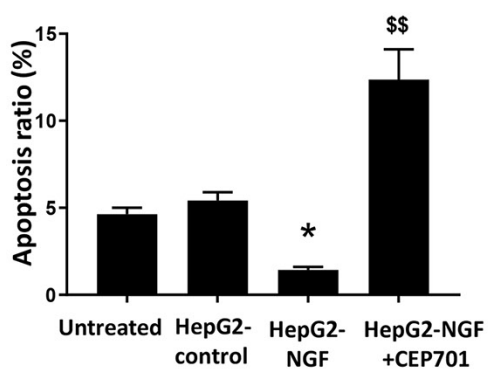

Figure 6. Effect of NGF on anoikis resistance and apoptosis. (A) HepG2 cells cultured in suspension culture model. Images were acquired with an inverted microscope (10x magnification) (B) Flow cytometry of HepG2 cells. (C) Apoptosis ratio of HepG2 cells. Data are presented as the mean \pm SEM. ${ }^{*}<0.05$ vs. HepG2-control and untreated group. ${ }^{\$} \mathrm{P}<0.01$ vs. HepG2-NGF cells without CEP701 treatment (one-way ANOVA). NGF, nerve growth factor.

CEP701 can prevent NGF-promoted cell motility (Fig. 2). Moreover, NGF overexpression-induced F-actin rearrangement can be prevented by CEP701 (Fig. 5). The effect of CEP701 on cell anoikis resistance and apoptosis was further examined in HepG2-NGF cells cultured in the suspension culture model. Notably, it was identified that $10 \mathrm{mg} / \mathrm{l} \mathrm{CEP701}$ prevented anoikis resistance and increased the cell apoptosis ratio (Fig. 6). 


\section{Discussion}

The primary aim of the present study was to determine the association of NGF, which is reportedly involved in breast and prostate cancer cell death and survival $(15,35)$, with liver cancer progression. In the present study, it was observed that NGF overexpression in HepG2 cells could disrupt cell polarity and promote cell motility. Additionally, NGF overexpression could induce EMT and actin cytoskeleton rearrangement in HepG2 cells. Furthermore, NGF could enhance anoikis resistance and prevent the apoptosis of HepG2 cells. Collectively, these data support the hypothesis that NGF signaling serves a critical role in the invasion and metastasis of liver cancer.

Cell polarization is required for several cellular processes, including differentiation, migration, morphogenesis and motility $(33,36)$. Disruption of cell polarity can disrupt normal cell behavior, resulting in the cancer initiation and progression $(11,33)$. Furthermore, disruption of cell polarity can initiate EMT, which is required for cancer cell migration and invasion $(12,36)$. Conversely, EMT can alter the function of polarity complexes and induce the loss of epithelial polarity (37-39). Similar to numerous other growth factors and cytokines (40-42), the current in vitro model data obtained from scratch-induced migration experiments demonstrated that NGF overexpression in HepG2 cells could promote cell motility and induce defective cell polarity. Consistent with these findings, NGF could induce a cadherin switch and vimentin expression in HepG2 cells, indicating that NGF can initiate EMT. To the best of our knowledge, the present study was the first to report that NGF was involved in liver cancer progression, especially in cancer cell invasion and metastasis, in addition to cell death and survival.

Previously, it has been reported that cell polarity proteins can regulate actin dynamics and cytoskeleton organization $(33,34)$. Conversely, increasing evidence suggests that the cytoskeleton can regulate cell polarity and provide the structural design and mechanical strength necessary for EMT $(38,39)$. Consistent with the polarity defect and EMT initiation in NGF-overexpressing HepG2 cells, the present study demonstrated that NGF overexpression could also induce F-actin redistribution and actin cytoskeleton development from circumferential bundles (circular actin pattern) to a system of parallel stress fibers. This rearrangement of the actin cytoskeleton is a prerequisite for cancer cell migration and invasion (39).

The mechanism via which NGF overexpression in HepG2 cells induces the loss of the apical-basal polarity and acquires the migratory phenotype remains unknown. Reportedly, neurotrophins, their receptors Trk and p75NTR and related signaling pathways serve an important role in the development of digestive cancer types (19,24). Moreover, Zhou et al (43) revealed that NGF receptor knockdown can elevate the expression level of endogenous p53 and result in hepatoprotective effects in HepG2 cells, while Indo5, which can inhibit the kinase activities of TrkA and TrkB in HepG2 cells, can suppress the growth of liver cancer(44). Although the expression of NGF is undetectable in healthy hepatocytes, NGF and Trk mRNA expression levels are significantly elevated in the liver tissue of the majority of patients with liver cancer, as well as in metastatic liver cancer cell lines, compared with those in healthy tissues or cell lines $(18,25)$. In agreement with previous studies $(45,46)$, the present study observed that a TrkA receptor inhibitor can prevent NGF-induced cell motility,
F-actin rearrangement and anoikis resistance, thus supporting an autocrine role for NGF signaling via its receptors in hepatocytes (47). However, the present study only used one exogenous overexpression system HepG2 cell line to investigate the role of NGF and its receptor in liver cancer progression. Due to this limitation, to use a different liver cancer cell line or primary cultured hepatocytes as another experimental model, to knockdown NGF or transfect a mutated NGF in HepG2 cell line or to study the detailed signaling downstream of NGF/Trk will help to clarify the role of NGF in regulating the cell motility and polarity.

In conclusion, the present study demonstrated that NGF overexpression could induce defective liver cancer cell polarity, EMT initiation and cell cytoskeleton rearrangement, which are required for tumor progression. The use of NGF as a biomarker or potential new target could lead to the development of new factors for diagnosis or for improving therapeutic strategies in liver cancer.

\section{Acknowledgements}

Not applicable.

\section{Funding}

This study received funding from the Scientific and Technological Innovation Foundation of Yantian District of Shenzhen City (grant no. 20190104).

\section{Availability of data and materials}

All data generated or analyzed during this study are included in this published article.

\section{Authors' contributions}

HL was involved in study conceptualization, funding and design, biochemical experiments, data analysis and interpretation, and study coordination and manuscript preparation. HH was involved in experimental design, data interpretation and analysis, and manuscript preparation. YY, WC, SZ and YZ were involved in the biochemical experiments, and data interpretation and analysis. All authors read and approved the final version of the manuscript.

\section{Ethics approval and consent to participate}

Not applicable.

\section{Patient consent for publication}

Not applicable.

\section{Competing interests}

The authors declare that they have no competing interests.

\section{References}

1. Nagtegaal ID, Odze RD, Klimstra D, Paradis V, Rugge M, Schirmacher P, Washington KM, Carneiro F and Cree IA; WHO Classification of Tumours Editorial Board: The 2019 WHO classification of tumours of the digestive system. Histopathology 76: $182-188,2020$. 
2. Bray F,Ferlay J, Soerjomataram I, Siegel RL, Torre LA and Jemal A: Global cancer statistics 2018: GLOBOCAN estimates of incidence and mortality worldwide for 36 cancers in 185 countries. CA Cancer J Clin 68: 394-424, 2018

3. Zheng R, Qu C, Zhang S, Zeng H, Sun K, Gu X, Xia C, Yang Z, Li H, Wei W, et al: Liver cancer incidence and mortality in China: Temporal trends and projections to 2030. Chin Jl Cancer Res 30: 571-579, 2018.

4. Fukata M, Nakagawa M and Kaibuchi K: Roles of Rho-family GTPases in cell polarisation and directional migration. Curr Opin Cell Biol 5: 590-597, 2003.

5. Woodham EF and Machesky LM: Polarised cell migration: Intrinsic and extrinsic drivers. Chin J Cancer Res30: 25-32, 2014.

6. Royer C and Lu X: Epithelial cell polarity: A major gatekeeper against cancer? Cell Death Differ 18: 1470-1477, 2011.

7. Jung HY, Fattet L, Tsai JH, Kajimoto T, Chang Q, Newton AC and Yang J: Apical-basal polarity inhibits epithelial-mesenchymal transition and tumour metastasis by PAR-complex-mediated SNAI1 degradation. Nat Cell Biol 21: 359-371, 2019.

8. Lee M and Vasioukhin V: Cell polarity and cancer-cell and tissue polarity as a non-canonical tumor suppressor. J Cell Sci 121: 1141-1150, 2008.

9. Larue L and Bellacosa A: Epithelial-mesenchymal transition in development and cancer: Role of phosphatidylinositol 3' kinase/AKT pathways. Oncogene 24: 7443-7454, 2005.

10. Tsai JH and Yang J: Epithelial-mesenchymal plasticity in carcinoma metastasis. Genes Dev 27: 2192-2206, 2013.

11. Yang J and Weinberg RA: Epithelial-mesenchymal transition: At the crossroads of development and tumor metastasis. Dev Cell 14: 818-829, 2008

12. Moreno-Bueno G, Portillo F and Cano A: Transcriptional regulation of cell polarity in EMT and cancer. Oncogene 27: 6958-6969. 2008

13. Lewin GR and Barde YA: Physiology of the neurotrophins. Annu Rev Neurosci 19: 289-317, 1996.

14. Hetman M and Xia Z: Signaling pathways mediating anti-apoptotic action of neurotrophins. Acta Neurobiol Exp (Wars) 60: 531-545, 2000 .

15. Bradshaw RA, Pundavela J, Biarc J, Chalkley RJ, Burlingame AL and Hondermarck H: NGF and ProNGF: Regulation of neuronal and neoplastic responses through receptor signaling. Adv Biol Regul 58: 16-27, 2015.

16. Yoon SO, Casaccia-Bonnefil P, Carter B and Chao MV: Competitive signaling between TrkA and p75 nerve growth factor receptors determines cell survival. J Neurosci 18: 3273-3281, 1998.

17. Frade JM, Rodríguez-Tébar A and Barde YA: Induction of cell death by endogenous nerve growth factor through its p75 receptor. Nature 383: 166-168, 1996.

18. Tokusashi Y, Asai K, Tamakawa S, Yamamoto M, Yoshie M, Yaginuma Y, Miyokawa N, Aoki T, Kino S, Kasai S, et al: Expression of NGF in hepatocellular carcinoma cells with its receptors in non-tumor cell components. Int J Cancer 114: 39-45. 2005

19. Kishibe K, Yamada Y and Ogawa K: Production of nerve growth factor by mouse hepatocellular carcinoma cells and expression of TrkA in tumor-associated arteries in mice. Gastroenterology 122 1978-1986, 2002.

20. Garrido MP, Torres I, Avila A, Chnaiderman J, ValenzuelaValderrama M, Aramburo J, Oróstica L, Durán-Jara E, Lobos-Gonzalez L and Romero C: NGF/TRKA decrease miR-145-5p levels in epithelial ovarian cancer cells. Int J Mol Sci 21, 7657, 2020

21. Faulkner S, Griffin N, Rowe CW, Jobling P, Lombard JM, Oliveira SM, Walker MM and Hondermarck H: Nerve growth factor and its receptor tyrosine kinase TrkA are overexpressed in cervical squamous cell carcinoma. FASEB Bioadv 2: 398-408, 2020

22. Blondy S, Christou N, David V, Verdier M, Jauberteau MO, Mathonnet M and Perraud A: Neurotrophins and their involvement in digestive cancers. Cell Death Dis 10: 123, 2019.

23. Yu X, Liu Z, Hou R, Nie Y and Chen R: Nerve growth factor and its receptors on onset and diagnosis of ovarian cancer. Oncol Lett 14 2864-2868, 2017

24. Demir IE, Tieftrunk E, Schorn S, Friess H and Ceyhan GO: Nerve growth factor \& TrkA as novel therapeutic targets in cancer. Biochim Biophys Acta 1866: 37-50, 2016.

25. Berretta M, Cavaliere C, Alessandrini L, Stanzione B, Facchini G, Balestreri L, Perin T and Canzonieri V: Serum and tissue markers in hepatocellular carcinoma and cholangiocarcinoma: Clinical and prognostic implications. Oncotarget 8: 14192-14220, 2017.

26. Han P, Fu Y, Liu J, Wang Y, He J, Gong J, Li M, Tan Q, Li D, Luo $\mathrm{Y}$, et al: Netrin-1 promotes cell migration and invasion by down-regulation of BVES expression in human hepatocellular carcinoma. Am J Cancer Res 5: 1396-1409, 2015.
27. Yan W, Han P, Zhou Z, Tu W, Liao J, Li P, Liu M, Tian D and Fu Y: Netrin-1 induces epithelial-mesenchymal transition and promotes hepatocellular carcinoma invasiveness. Dig Dis Sci 59: 1213-1221, 2014

28. Etienne-Manneville $\mathrm{S}$ and Hall A: Cdc42 regulates GSK-3beta and adenomatous polyposis coli to control cell polarity. Nature 421 753-756, 2003.

29. Zhang S, Schafer-Hales K, Khuri FR, Zhou W, Vertino PM and Marcus AI: The tumor suppressor LKB1 regulates lung cancer cell polarity by mediating cdc 42 recruitment and activity. Cancer Res 68: 740-748, 2008

30. Frisch SM and Francis H: Disruption of epithelial cell-matrix interactions induces apoptosis. J Cell Biol 124: 619-626, 1994.

31. Yadav S, Puri S and Linstedt AD: A primary role for golgi positioning in directed secretion, cell polarity, and wound healing. Mo Biol Cell 20: 1728-1736, 2009.

32. Ravichandran Y, Goud B and Manneville JB: The Golgi apparatus and cell polarity: Roles of the cytoskeleton, the Golgi matrix, and Golgi membranes. Curr Opin Cell Biol 62: 104-113. 2019.

33. Piroli ME, Blanchette JO and Jabbarzadeh E: Polarity as a physiological modulator of cell function. Front Biosci (Landmark Ed) 24: 451-462, 2019

34. Elias BC, Das A, Parekh DV, Mernaugh G, Adams R, Yang Z, Brakebusch C, Pozzi A, Marciano DK, Carroll TJ and Zent R: Cdc42 regulates epithelial cell polarity and cytoskeletal function during kidney tubule development. J Cell Sci 128: 4293-4305, 2015.

35. Melck D, De Petrocellis L, Orlando P, Bisogno T, Laezza C, Bifulco M and Di Marzo V: Suppression of nerve growth factor Trk receptors and prolactin receptors by endocannabinoids leads to inhibition of human breast and prostate cancer cell proliferation. Endocrinology 141: 118-126, 2000.

36. Gandalovičová A, Vomastek T, Rosel D and Brábek J: Cell polarity signaling in the plasticity of cancer cell invasiveness. Oncotarget 7: 25022-25049. 2016

37. Fuertes-Alvarez S, Maeso-Alonso L, Villoch-Fernandez J, Wildung M, Martin-Lopez M, Marshall C, Villena-Cortes AJ, Diez-Prieto I, Pietenpol JA, Tissir F, et al: p73 regulates ependymal planar cell polarity by modulating actin and microtubule cytoskeleton. Cell Death Dis 9: 1183, 2018.

38. Lomakin AJ, Lee KC, Han SJ, Bui DA, Davidson M, Mogilner A and Danuser G: Competition for actin between two distinct F-actin networks defines a bistable switch for cell polarization. Nat Cell Biol 17:1435-445, 2015

39. Olson MF and Sahai E: The actin cytoskeleton in cancer cell motility. Clin Exp Metastasis 26: 273-287, 2009.

40. Witsch E, Sela M and Yarden Y: Roles for growth factors in cancer progression. Physiology (Bethesda) 25: 85-101.2010.

41. Okamoto M, Koma YI, Kodama T, Nishio M, Shigeoka M and Yokozaki H: Growth differentiation factor 15 promotes progression of esophageal squamous cell carcinoma via TGF- $\beta$ type II receptor activation. Pathobiology 87: 100-113, 2020.

42. West NR, McCuaig S, Franchini F and Powrie F: Emerging cytokine networks in colorectal cancer. Nat Rev Immunol 15: 615-629, 2015.

43. Zhou X, Hao Q, Liao P, Luo S, Zhang M, Hu G, Liu H, Zhang Y, Cao B, Baddoo M, et al: Nerve growth factor receptor negates the tumor suppressor p53 as a feedback regulator. Elife 5: e15099, 2016.

44. Luo T, Zhang SG, Zhu LF, Zhang F, Li W, Zhao K, Wen XX, Yu M, Zhan YQ, Chen H, et al: A selective c-Met and Trks inhibitor Indo5 suppresses hepatocellular carcinoma growth. J Exp Clin Cancer Res 38: 130. 2019

45. Lagadec C, Meignan S, Adriaenssens E, Foveau B, Vanhecke E, Romon R, Toillon RA, Oxombre B, Hondermarck H and Le Bourhis X: TrkA overexpression enhances growth and metastasis of breast cancer cells. Oncogene 28: 1960-1970, 2009.

46. Festuccia C, Muzi P, Gravina GL, Millimaggi D, Speca S, Dolo V, Ricevuto E, Vicentini $\mathrm{C}$ and Bologna M: Tyrosine kinase inhibitor CEP-701 blocks the NTRK1/NGF receptor and limits the invasive capability of prostate cancer cells in vitro. Int J Oncol 30: 193-200, 2007.

47. Tsai MS, Lee PH, Sun CK, Chiu TC, Lin YC, Chang IW, Chen PH and Kao YH: Nerve growth factor upregulates sirtuin 1 expression in cholestasis: A potential therapeutic target. Exp Mol Med 50: e426. 2018.

This work is licensed under a Creative Commons Attribution-NonCommercial-NoDerivatives 4.0 International (CC BY-NC-ND 4.0) License. 